\title{
O IMPOSTO SOBRE O VALOR AGREGADO: HISTÓRICO E POSSIBILIDADE DE IMPLEMENTAÇÃO NO BRASIL
}

\section{RESUMO}

\author{
Henrique Ribeiro Cardoso ${ }^{1}$ \\ Luciana de Aboim Machado ${ }^{2}$ \\ Yuri Matheus Araujo Matos ${ }^{3}$ \\ Yago de Santana Silva ${ }^{4}$
}

O objetivo do presente artigo é discussão da pertinência da implementação do imposto sobre o valor a grega do (IVA) no cenário nacional, a o tomar como base o histórico de tal taxação em outros Estados. A metodologia utilizada é o estudo hermenêutico literário, através de análise de livros, decisões judiciais e administrativas, artigos científicos e notícias. No que tange à relevância do presente estudo, resta cla ro que a reformulação tributária no Brasil é indispensável para a contenção de fraudes, a lém de contribuir para a necessária eficiência no recolhimento de taxas. Desse modo, é possível obter como um dos principais resultados a pertinência da implementação do imposto de valor a gregado no Brasil. Baseado nas lições de Waldemir Luis Quadros foi possível adentrar nas implicações teóricas pertinentes à presente discussão e delinear as possíveis benesses aos sistema de tributação bra sileiro.

Palavras-chave: Imposto sobre o Valor Agregado; Reforma tributária; Justiça fiscal.

Submetido em: 14/01/2021

Aprovado em: 30/05/2021

DOI: https://doi.org/10.37497/revcampojur.v9i1.664

\footnotetext{
${ }^{1}$ Pós-doutorado em Democracia e Direitos Humanos (IGC - Universidade de Coimbra) e Pós-doutorado em Direitos Humanos e Desenvolvimento (PPGCJ/UFPB); Professor do Programa de Pós-Graduação da Universidade Federal de Sergipe (PRODIR/UFS) Promotor de Justiça Titular da Fazenda Pública em Sergipe (MPSE). Email: henrique@mpse.mp.br Orcid:https://orcid.org/0000-0001-8592-7224

2 Pós-Doutora em Direito Constitucional na Universidade Federal da Bahia - UFBA e na Università degli Studi G. d'Annunzio di Chieti-Pescara - UDA. Professora Associada e Coordenadora do Programa de PósGraduação em Direito da Universidade Federal de Sergipe - UFS. Email: lucianags.adv@uol.com.br Orcid: https://orcid.org/0000-0001-5724-6368

3 Mestrando em Direito da Universidade Federal de Sergipe (PRODIR/UFS). Financiamento: CAPES. Email: mestradodireitoufs@gmail.com Orcid: https://orcid.org/0000-0003-4322-359X

${ }^{4}$ Membro ativo do Grupo de Trabalho, PIBIC: "Cidadania e Integridade: Compliance como instrumento de paz social", da Universidade Federal de Sergipe. Discente de Direito na Universidade Federal de Sergipe. Email: yago.1999@hotmail.com.br Orcid: https://orcid.org/0000-0002-5763-8449
}

\section{Campo Jurídico|Barreiras (BA) | v.9 |e664| p.01-22 |Janeiro-Junho|2021}




\title{
THE ADDED VALUE TAX: HISTORIC AND POSSIBILITY OF IMPLEMENTATION IN BRAZIL
}

\begin{abstract}
The purpose of this article is to discuss the relevance of implementing the value added tax (VAT) in the national scenario, based on the history of such taxation in other States. The methodology used is the literary hermeneutic study, through the analysis of books, judicial and administrative decisions, scientific articles and news. Regarding the relevance of the present study, it is clear that the tax reformulation in Brazil is essential to contain fraud, in addition to contributing to the necessa ry efficiency in the collection of fees. Thus, it is possible to obtain as one of the main results the pertinence of implementing the value added tax in Brazil. Based on the lessons of Waldemir Luis Quadros, it was possible to enter into the theoretical implications relevant to this discussion and outline the possible benefits to the Brazilian tax system.
\end{abstract}

Keywords: Value Added Tax; Tax reform; Tax justice.

\section{INTRODUÇÃO}

A metodologia utilizada é o estudo hermenêutico literário, através de análise de livros, decisões judiciais e administrativas, artigos científicos e notícias. Além disso, análise quantitativa das entrevistas com parlamentares. Por fim, o estudo comparativo entre os sistemas tributários de diversos países, em especial integrantes da União Europeia, em cotejo com o modelo brasileiro.

A provocação causada pelo tema da possibilidade de implementação do Imposto sobre Valor Agregado (IVA), no âmbito nacional, orientou a produção do presente trabalho. A partir desta inquietude, este estudo objetiva analisar criticamente o atual Sistema Tributário Brasileiro e as possibilidades de melhoria advindas da recepção do IVA no país, diante das transformações da ocorridas na sociedade brasileiro ao longo do tempo.

O debate tributário nacional tem adquirido relevante repercussão nos meios de comunicação e no senso comum da sociedade, seja pelos possíveis impactos nas fontes gerad oras de empregos, seja pela percepção fática d a cobrança de tributos. Desta maneira, a reforma tributária tem sido uma tônica majoritária no plano nacional.

Delineia-se como problemática fundante quais motivações relegam o Brasil ao não reformismo tributário, à negação de implementações sensíveis e à dificuldade de efetivar a simplificação tributária nacional. A elevada carga de tributação brasileira imprime força negativa sobre a eficiência tributária e competitividade ind ustrial/comercial, abrindo espaço para um necessário debate sobre reformulação fiscal. Surge como tendência mundial a unificação de impostos. Nesse sentido, o Imposto sobre

Campo Jurídico|Barreiras (BA) | v.9 |e664| p.01-22 |Janeiro-Junho|2021 
valor agregado (IVA) tornou-se uma das possibilidades mais viáveis ao bom sistema tributário.

Por esta razão são identificadas as principais necessidades de melhoria no Sistema Tributário Nacional. Em seguida, discutidas as peculiaridades de uma possível implementação do IVA, a fim de verificar se há espaço para atualização tributária, e quais reverberações são possíveis e esperadas.

Adota-se como hipótese lastradora a falta histórica de iniciativa do poder legítimo para a propositura de reformas tributárias contundentes, mesmo em face de evidente necessidade nacional. Como hipótese secundária é observada a necessidade de um imposto sobre o consumo neutro, isonômico, de simples aplicação cotidiana e com distribuição de receitas justa.

\section{O IMPOSTO SOBRE VALOR AGREGADO E SUAS CONSEQUÊNCIAS}

Os recentes debates sobre a necessidade de uma sensível reforma tributária brasileira evidenciam a urgência de o setor tributário reavaliar as demandas sociais e dos mercados nacionais e internacionais. As referidas mudanças na forma e na essência tributária devem advir de um pacote de alterações que ocorram na atual estrutura constitucional e legislativa de impostos, de taxas e de contribuições vigentes.

Relevantes pleitos tributários estão mais eloquentes no debate político e administrativo do Brasil, seja pela materialidade dos resultados nos mercados industriais e trabalhistas (a exemplo das nocivas resultantes do conhecido "Custo Brasil"5), seja pela possível falta de eficiência tributária e má concatenação de esforços para isonomia fiscal brasileira.

Os mencionados fatos reaquecem as discussões tributárias sobre a necessidade de implementação do Imposto sobre o Valor Agregado ou Adicionado (IVA), de natureza

\footnotetext{
${ }^{5}$ Em relação ao "Custo Bra sil", pode ser delinea do como um conjunto normativas tributá rias que relega o país aos espaços menos competitivos e eficientes. Nas lições de Costa e Gameiro (2005), não há uma definição objetiva sobre a expressão, contudo delineia que: "Alguns autores definem Custo Brasil como o conjunto de todos os gastos internos que acabam onerando produtos ou serviços brasileiros. Outros o descrevem como sendo impostos em cascata, corrupção na máquina burocrática, distorções presentes na estrutura tributária e custos com transportes terrestres, portos e comunicações. Existe, ainda, quem trate Custo Bra sil relaciona do à s exportações, enfa tizando as desigualda des comercia is que o Bra sil enfrenta em relação a grandes potências mundiais". (COSTA; GAMEIRO, 2005, p. 1)
}

Campo Jurídico|Barreiras (BA) | v.9 |e664| p.01-22 |Janeiro-Junho|2021 
indireta, para a tributação do consumo genérico, que incidiria sobre a cadeia produtiva e de distribuição de mercadorias para o consumidor final ${ }^{6}$.

Historicamente o IVA foi idealizado e gestado teoricamente na França, em meados século XX, como uma das primeiras medidas da harmonização tributária do país, que posteriormente assumiu a vanguarda de tal intento. A essencial do referido imposto rapidamente se alastrou para a Europa Ocidental, ganhando, posteriormente, a atenção de países no continente americano (BALTHAZAR, 2008, p. 248) ${ }^{7}$.

Relevante questão em favor da substituição de uma gama de impostos brasileiros pelo IVA seria que tal valor agregado incidiria sobre a riqueza gerada pela sociedade empresária, taxando, assim os ativos correspondentes às efetivas entradas, excluindo-se os bens e serviços consumidos para tal feitura de capital. Destarte, o valor final do produto não era agravado pelo imposto, independentemente do número de transações em sua produção e circulação até o consumo final (GUIMARÃES, 2006).

Destaca-se, ademais, que do sistema tributário atual poderia ser otimizado com a implantação do IVA, falecendo sobremaneira aspectos da guerra fiscal atualmente verificada no Brasil. Sob a luz da Constituição da República Federativa do Brasil de 1988, estados e municípios têm autonomia tributária, estabelecendose, na prática, uma livre concorrência para que algumas sociedades empresárias obtenham a redução nos impostos estaduais e municipais.

Outro aspecto benéfico ao sistema tributário do Brasil seria a criação de barreiras contra fraudes fiscais. Adotando-se o modelo clássico de tributação do consumo, a arrecadação é fracionada ao longo de toda a cadeia de produção, recrudescendo as possibilidade de fraudes fiscais - em razão das dificuld ades de processamento e cobrança.

$\mathrm{Na}$ contramão da superficialidade, tal "incentivo fiscal” pode parecer interessante para as entidades. Contudo, é em tal ponto que uma das questões mais

\footnotetext{
${ }^{6}$ Conforme leciona Montoro Filho (1992): "Valor Adicionado é definido como o resultado da diferença entre o valor dos bens e serviços vendidos pela empresa, quaisquer que sejam, e o valor dos bens e serviços comprados pela empresa junto a outras empresas. Significa assim, o acréscimo de valor que a empresa incorpora a o bem na cadeia produtiva". (MONTORO,1992, p.27)

${ }^{7}$ Nesse aspecto explica: "Foi na França que, como consequência das reformas realiza das durante mais de 40 anos, apresentaram-se as condições para a instauração do imposto sobre o valor agregado, com seus elementos e característica s ta is como conhecemos hoje. O grande mérito do legislador francês foi ter sabido conjugar todos os elementos que resultaram da evolução do sistema de imposição do volume de negócios, construindo os contornos próximos do sistema a tualmente aplica do por todos os Esta dos membros da União Europeia”. (BALTHAZAR, 2008,p. .248)
}

Campo Jurídico|Barreiras (BA) | v.9 |e664| p.01-22 |Janeiro-Junho|2021 
relevantes se estabelece, haja vista que, em médio ou longo prazo, a arrecad ação geral do país diminui.

Ademais, a chamada guerra fiscal ocorre especialmente entre os estados brasileiros, atualmente responsáveis pela cobrança do ICMS. Portanto, a implementação do Imposto sobre o Valor Agregado simplificaria o sistema tributário nacional e concatenaria a isonomia fiscal, resultando, inclusive em menores perdas de tributos pelo Estado brasileiro, com a reunião de diversos impostos, especialmente o ICMS, em apenas um $^{8}$.

Importa expor que os parceiros do Brasil no MERCOSUL (à exceção da Venezuela, suspensa do bloco) possuem um IVA nacional, demonstrando certo descompasso do sistema tributário nacional frente à atualidade.

Em síntese, a proposta delineia que o Estado tributaria simplificadamente as relações de consumo, da produção à comercialização final das mercadorias. Atualmente o IVA cada vez mais é apresentado como alternativa viável e eficiente, na busca da majoração das receitas de arrecadação tributária, reduzindo, paralelamente, custos fiscalizatórios. Destarte, tal imposto acarreta, especialmente, que o risco de fraude tributária seja minorado ao longo do processo.

\section{RELEVÂNCIA PRÁTICA DO IMPOSTO SOBRE O VALOR AGREGADO}

No modelo de tributação do consumo atual brasileiro a alíquota dos serviços é baixa, se comparada à das mercadorias. Enquanto isso, é reflexo da globalização e avanço econômico a realocação da atividade produtiva da indústria para o setor terciário.

Por outro lado, os municípios, responsáveis pelo Imposto sobre Serviços de Qualquer Natureza - ISS, possuem estrutura de cobrança e controle inferior à demandada pela sociedade contemporânea e mercado tecnológico. Consequentemente, a tributação dos serviços culmina em tendência de vazios impositivos e quebra da isonomia físcal (GUIMARÃES, 2007, p. 63)

\footnotetext{
${ }^{8} \mathrm{~A}$ formatação trazida pela Constituição bra sileira foi no sentido de que houvesse: "diminuição do campo de competência da União em contrapartida ao aumento do número de impostos competentes a estados e municípios. Tratou-se de um primeiro passo para o aumento da autonomia relativa das unidades subnaciona is e para o forta lecimento do sistema federativo bra sileiro". (CARDOZO, 2010,p. 40)
}

Campo Jurídico|Barreiras (BA)| v.9 |e664| p.01-22 |Janeiro-Junho|2021 
Em relação ao ICMS, imposto integral e integrado (COÊLHO, 2007, p. 530), seu montante integra a própria base de cálculo, no chamado "cálculo por dentro" 9 . Além de ocasionar dificuldades para a aferição do imposto efetivo, provoca o aumento do imposto pela via transversa ${ }^{10}$.

Nas relações interestaduais, além disso, aplica-se um modelo misto, com alíquota fixa de tributação na origem e outra a ser adimplida no destino, correspondente à diferença entre o valor estabelecido nesta e naquela ${ }^{11}$, acarretando evidente dificuldades no seu cálculo e recolhimento.

Não é diferente nas exportações. Estas deveriam ser desoneradas, e há previsão de imunidade constitucional, inclusive com restituição de créditos. Entretanto, os resquícios de cumulatividade presentes em alguns tributos impedem que isto na prática ocorra ${ }^{12}$.

Questões semelhantes às enfrentadas pelo Brasil atual fizeram com que os autores portugueses, antes da implementação do IVA, classificassem o seu próprio sistema como um fator de fraude, dificuldade de processamento pela própria Administração e lentidão na justiça fiscal (DOS SANTOS, 2007, p. 225).

Trata-se de um modelo de difícil articulação (inclusive nos processos de alteração das suas normas), que favorece a discriminação, cria circunstâncias favoráveis à evasão (fraude induzida), promove clima de concorrência fiscal entre as unidades federativas, com suas alíquotas não harmonizadas e possui objetivos difusos ${ }^{13}$. Ademais, não é neutro $^{14}$ - isto é, influencia diretamente na cadeia produtiva, beneficiando alguns

\footnotetext{
${ }^{9}$ Ao contrá rio do ICMS, o IPI é ca lcula do "por fora". Ou seja, o imposto não integra a sua própria base de cálculo. Por esta razão as alíquotas nomina is podem alçar pa tamares maiores (acima dos 300\%, inclusive). Há uma explica ção histórica para este fa to ": "Quando se introduziu o ICM, em 1965, aproveitou-se não só a concepção teórica, como a própria experiência prática e administrativa do velho imposto de consumo, que passou a receber esta designação na mesma época (1965)" (MELO, 1991,p. 7).

10 "Esta técnica de cálculo se nos apresenta manifestamente nociva, vez que acaba por ressu scitar os denominados "impostos sobre impostos", provocando, por via transversa, a elevação de alíquotas." (MEIRELLES, 2000, p. 106)

11 "A a líquota bá sica para operações internas (produtos e serviços) é de 17\%, e sendo seletiva em função da essencialidade do produto chega a $25 \%$ para certos bens. No que se refere ao destino, as alíquotas podem variar: 7\% (maioria das regiões; 12\% (sudeste/sul) e 13\% (exterior). O Senado Federal, mediante resolução, poderá estabelecer as alíquota s a plicá veis às operações e prestações interesta dua is". (MEIRELLES, 2000, p. 106)

${ }^{12}$ Como exemplo, a dificuldade inerente ao próprio cálculo dos impostos incidentes sobre os insumos, a constituírem créditos futuros de ICMS. A lógica dos impostos sobre o consumo é que incida somente no país de destino, como se observa da litera tura tributária: "Impostos de consumo são aqueles que se pagam no contexto da utilização de bens e serviços fina is no país onde são consumidos." (CNOSSEN, 1990, p. 3)

13 Um exemplo: "Quando pensamos em contribuinte dos impostos sobre o consumo no Bra sil, deve-se ater às três diferentes hipóteses de incidência”. (COSTA, 2014,p. 77)

14 "Manteve-se uma cumulatividade residual nociva, tanto no IPI quanto no ICMS, fator que, desde as origens, mesmo na década de sessenta, moldava ta is impostos de modo mais desvantajoso face ao modelo europeu (IVA)." (DERZI, 2007,P. 529)
}

Campo Jurídico|Barreiras (BA)| v.9 |e664| p.01-22 |Janeiro-Junho|2021 
empresários em prejuízo de outros, sem qualquer motivo econômico. Possui ainda base de tributação reduzida. Assim sendo, sua receita tende à redução gradual, pelos impactos econômicos causados.

Por esta razão adotou-se o sistema IVA, posto em prática primeiramente na França, mas teorizado anteriormente na Alemanha e nos Estados Unidos da América pós-Segunda Guerra Mundial ${ }^{15}$. O Imposto sobre o Valor Agregado é um imposto neutro $^{16}$ e não discriminatório (LOPES, 2006, p. 41), com transações intracomunitárias europeias (entre os países membros do bloco) não gravadas, e contrário à fraude e evasão fiscal pela troca de informações, articulação intergovernamental e alíquotas harmonizadas.

Consequentemente, possui clima de cooperação institucional entre Estados e agentes econômicos. Logo, seu clima de abertura à mudança é consensual e gradativo. A base tributável é alargada - ou seja, incide de forma ampla sobre vários bens e serviços, evitando assim que alguns sejam beneficiados e outros prejudicados). Desta maneira, identifica-se a possibilidade do IVA Europeu de tendência ao crescimento arrecadatório, ao contrário do modelo brasileiro (GUIMARÃES, 2007, p. 67).

Em virtude dos benefícios apresentados, o sistema IVA se espalhou pelo mundo. Todavia, ainda não alcançou o Brasil (FALCÃO, 2007, p. 612). ${ }^{17}$ Dentre outros motivos

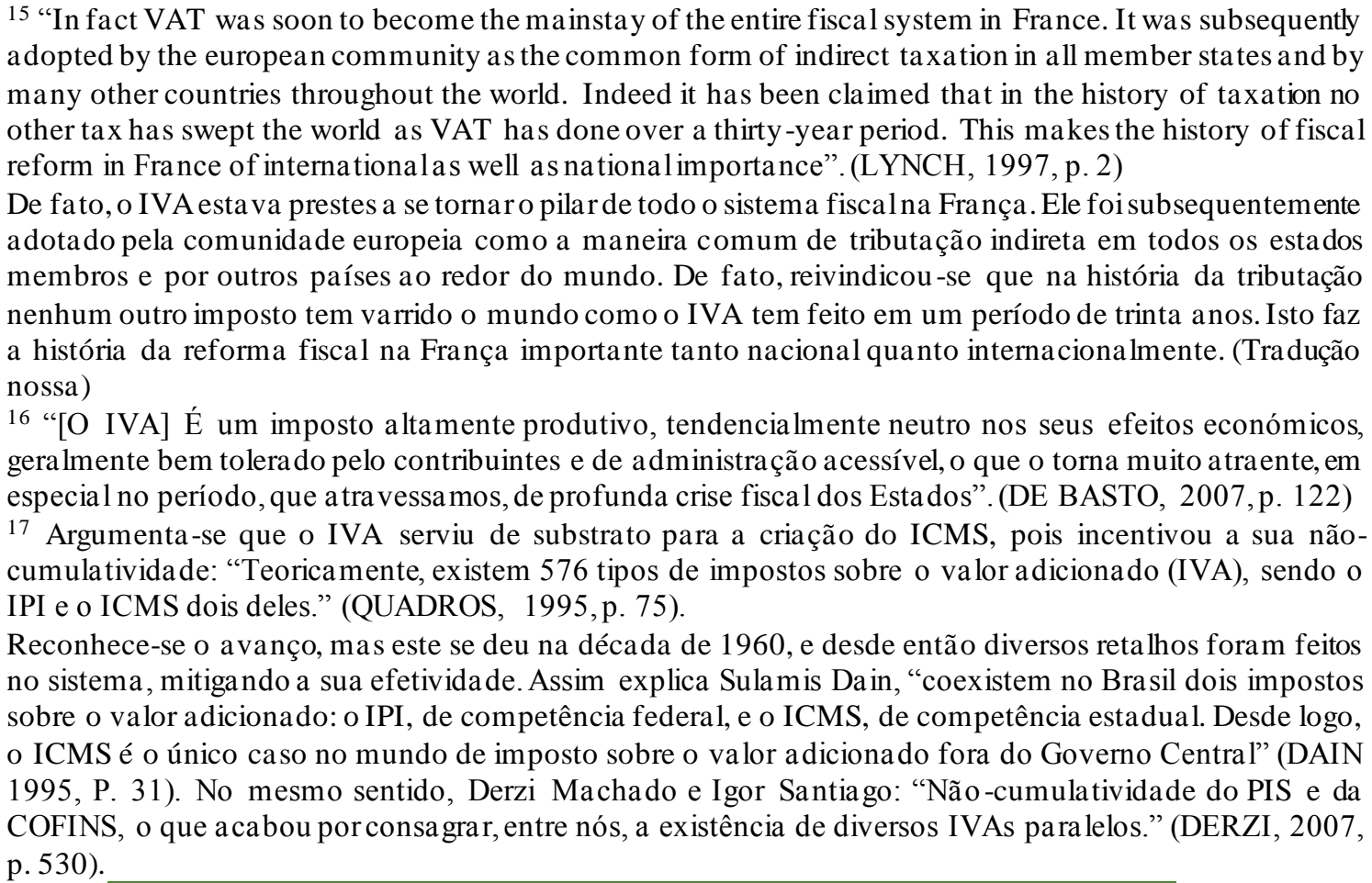

Campo Jurídico|Barreiras (BA)| v.9 |e664| p.01-22 |Janeiro-Junho|2021 
identificados, por possuir caráter "indolor" e grande eficiência ao corrigir imperfeições da tributação da renda (FALCÃO, 2007, p. 613) ${ }^{18}$. A evolução econômica e tecnológica, todavia, permite o desenvolvimento da tributação atual brasileira ${ }^{1920}$.

Mediante a adoção do Imposto sobre o Valor Agregado, em substituição ao ISS, ICMS e IPI, simplifica-se a consideravelmente a legislação, assim como as obrigações administrativas, para os contribuintes e as administrações fiscais ${ }^{21}$. Com redução dos riscos de fraude, alargamento da base tributária e restrição às renúncias fiscais (SARAIVA FILHO, 2007,p. 662) há incremento no nível de receitas dos Estadosmembros. A neutralidade em termos concorrenciais permite o crescimento econômico, com redução do benefício a alguns poucos empresários próximos do Estado (PALMA, 2007, p. 181).

Demonstrada viabilidade jurídico-econômica (TORRES, 2007, p. 24, 32) o IVA deve cobrir tod as as etapas de prod ução, importação, transporte e consumo, mediante uma redistribuição das competências no federalismo fiscal. A União passaria a legislar sobre o tema, e a administração seria compartilhada, assim como o julgamento dos litígios decorrentes da aplicação (TORRES, 2007, p. 34-35).

A autonomia dos estados seria preservada mediante o repasse direto e imediato de receitas aos entes federativos, mediante critérios estabelecidos em Lei Complementar,

\footnotetext{
Tendo em vista que a lógica do Imposto Sobre o Valor Agregado é a simplicidade e eficiência, o uso de mais de um imposto de natureza semelhante para tra tar de fato gera dor conceitualmente próximo desvirtua a própria ideia do IVA e faz com que haja perda de eficácia.

18 Por esta razão teve crescimento acentuado nas últimas décadas nas nações de economia mais desenvolvida. Evoluiu-se na técnica de legislação e arrecadação, mas infelizmente o Brasil não acompanhou as tendências mundiais.

${ }^{19}$ Dentre outros parâmetros, a lição interna cional(por exemplo, de Moçambique) demonstrou ser "Elá stico na geração da s receitas, a companhando as va riações do rendimento e produto na ciona is; neutral [...] não se constituindo como factor influenciador das decisões [...] favorável ao investimento produtivo [...] administrativamente mais eficiente [...] redução da economia paralela [...] (facturas); possibilitando o desenho de um imposto com taxas [alíquotas] mais baixas, já que tendencialmente é um imposto mais produtivo graças à sua vasta base de incidência”. (CHANGA, 2007, p. 470)

20 "A introdução do IVA no modelo tributário bra sileiro pode não ser a solução para que o país supere todas as dificuldades [...] mas certamente contribuirá para que se possa simplificar, racionalizar, e melhorar a situação de desarmonia presente em nosso ordenamento tributário, de forma a favorecero crescimento do país, e principalmente, no plano internacional, permitir a nossa competitividade" (ÁGUIA, 2007,p. 132) ${ }^{21}$ A experiência internacional, lecionada por Aboocar Changa ${ }^{21}$, mostrou que é possível a criação de um IVA descrito por ele como: "simples, de fácil administração [...] funcionando pelo método de crédito [...] limita do e reduzido número de isenções objectivas [...] taxa única, e taxa zero a plicá velàs exportações [...] incidindo em todos os estádios da cadeia económica, a té o retalho". Ele sugere que seja adotado o modelo de tributação geral, com "isenção de alguns sectores de atividade", como para pequenas empresas, por exemplo. Antes de mais nada, porém, afirma ser essencial a "elaboração de um prim eiro estudo sobre a base potencialdo IVA", mediante o a poio de assistência técnica, para que seja construído um pla no de ação específico. (CHANGA, 2007,p. 470-471)
}

Campo Jurídico|Barreiras (BA) | v.9 |e664| p.01-22 |Janeiro-Junho|2021 
através de fundo comum. Sua gestão, através de convênio deliberativo autônomo formado por todos os entes federativos, resguardada a participação dos municípios ${ }^{22}$.

Do exame literário foi identificada a sugestão de uma implementação gradual, mediante limitação inicial das alíquotas ICMS em no máximo cinco, para a criação do IVA em uma etapa posterior (ÁGUIA, 2007, p. 123). Dessa forma, pode-se obter o novo tributo com preservação do volume de receita (CHANGA, 2007, p. 475).

Quanto às renúncias fiscais, parte da literatura defende a vedação (ressalvados os dispositivos constitucionais), e outra a simples restrição à reserva de Lei Complementar. Em ambos os casos o $\mathrm{CONFAZ}^{23}$ não teria mais o poder de regrar acerca do tema.

Há discordâncias sobre a aplicação da progressividade do novo imposto, defendendo parte dos estudiosos alíquota única, outra parte alíquota única com adoção de accises (outros tributos específicos sobre alguns produtos, como bebidas), outros ainda o uso de três a cinco alíquotas de caráter progressivo (para manter certa seletividade fiscal), e há, por fim, a defesa de um IVA amplamente progressivo ${ }^{24}$.

Não se identificou discordâncias relevantes, entretanto, em relação ao aprofundamento da não-cumulatividade, com a adoção do regime do crédito financeiro (vinculado ao dinheiro movimentado, e não aos produtos) (ÁGUIA, 2007, p. 125).

Em relação à viabilidade econômica, não se observou obstáculo relevante na experiência internacional, nem nos estudos tributários brasileiros. Quanto à viabilidade jurídica, também não há óbice relevante (COSTA, 2014, p. 97). Por outro lado, no âmbito político, observou-se dificuldades.

A adoção do Imposto sobre o Valor Agregado tem sido usualmente conceituada como boa, mas aparentemente inviável (COSTA, 2014, p. 97) - modelo comum de argumentação utilizado para proteção contra interesse adverso, mesmo com baixo

\footnotetext{
22 "Maior integra ção dos Fiscos: seguindo os moldes do já viabiliza do no Super Simples [...] com nota fiscal eletrônica; cadastros sincronizados e Sistemas Públicos de Escrituração Digital (SPED). A base de dados, resultante da nota fiscal eletrônica, cria condições para ca librar a dequa damente as a líquotas e para estimar o impacto das mudanças para entes federados. Tudo isto permite equacionar os acúmulos de créditos, mediante a instituição de uma câmara de compensação entre empresas.” (SARAIVA FILHO, 2007,p. 662) ${ }^{23}$ Com o fim de reduzir a guerra fiscal, o CONFAZ regula as renúncias fiscais no Brasil, atualmente. Com a existência de um novo convênio para regulação tributária e criação de outro tributo, este trabalho do CONFAZ seria tornado desinteressante.

24 Dentre os críticos está Maurin Almeida Falcão, que afirma que "a percepção ingênua de que a progressividade seria o único meio de assegurar a justiça fiscal foi descartada tão logo as economias naciona is ganharam dimensões mundiais" (FALCÃO, 2007,p. 613)
}

Campo Jurídico|Barreiras (BA)| v.9 |e664| p.01-22 |Janeiro-Junho|2021 
substrato técnico (GALBRAITH, 1996, p. 5) ${ }^{25}$. Relevante fator apto a dificultar o processamento do IVA, por outro lado, está na baixa participação popular no debate inerente ao tema (GALBRAITH, 1996, p. 95)

Não se trata, na realidade, de simples empecilho à reforma da tributação do consumo. Sem a participação popular - em especial dos pequenos contribuintes - a reforma pode não obter o resultado proposto: ocasionaria simples mudanças institucionais, sem reflexo sobre o comportamento cotidiano. Desta maneira, é uma etapa essencial para a integração do ISS, ICMS e IPI em um Imposto sobre o Valor Agregado, de caráter geral e com competência legislativa federal e material comum entre a União, Estados, Municípios e Distrito Federal.

\section{REFORMA DA TRIBUTAÇÃO EUROPEIA}

Apesar do retardamento na realização de efetivas reformas da tributação do consumo, o Brasil possui a possibilidade de atenção e aprendizado, a partir das mudanças ocorrida sem outras nações. O sistema europeu, em especial, pode ser utilizado como parâmetro, observadas as peculiaridades locais, para o cuidado na inserção de um sistema eficiente.

Anteriormente à introd ução do IVA europeu, a sua tributação indireta já produzida uma fatia significativa de receita ${ }^{26}$, em decorrência do crescimento industrial ${ }^{27}$ e da redução proporcional dos impostos sobre a renda ${ }^{28}$ - esta, em virtude da diversidade de alocação monetária decorrente do mercado internacional e competitividade internacional por moeda.

\footnotetext{
${ }^{25}$ Frise-se também não possuir respaldo prático, pois foi rea liza da pesquisa entre os 513 deputados federais eleitos pelo G1, Grupo Globo, e 412 responderam um questionário geral. Dentre eles, $266(52 \%)$ se disseram fa vorá veis à a doção do Imposto sobre o Valor Agregado (IVA). Apenas 83 (16\%) apresentaram a lgum tipo de oposição à ideia, e outros 63 não respondera m à pergunta específica. Em síntese, há aptidão política suficiente para a aprovação a té mesmo de reformas constitucionais. O próprio poder executivo propôs diretamente a simplificação e unificação tributária. ( SCHULTZ, 2018)

26 "A realização do mercado interno teve reflexos importantes em sede de tributação indirecta, alguns em sede de tributação directa e qua se nulos em sede orçamental". (DOS SANTOS, 2007,p. 230)

${ }^{27}$ Por exemplo, "Estimou-se que a perda pela Holanda das grandes possessões indonésias, a pós a Segunda Guerra Mundial, foi compensa da pormeros dois anos de crescimento econômico interno". (GALBRAITH, 1996,p. 144)

28 "A tributação sobre o consumo passou a substituir as receitas perdidas em razão da necessidade de se a tenuar a tributação sobre o pa trimônio e a renda. [...] função social [...] a tributação sobre o consumo, a lém da natureza indolor, é uma forma de tributação indireta da renda. [...] redução do universo do contribuinte do imposto, as empresas [...] Apesar de a incidência do tributo ocorrer sobre uma massa de consumidores fina is de bens e serviços, o controle da administração é reduzido a o universo dos contribuintes de direito". (FALCÃO, 2007, p. 619)
}

Campo Jurídico|Barreiras (BA)| v.9 |e664| p.01-22 |Janeiro-Junho|2021 
O modelo de tributação dominante até então era o plurifásico em cascata, ou monofásico não cumulativo usando a técnica do anel (ring system), a exemplo de Portugal. Isto significa que a mesma alíquota era incidente sobre os produtos, em todas as suas operações, desde a produção até o consumidor final - sem o direito de creditamento das etapas anteriores. Outra Característica comum entre as administrações europeias era a estreita base de incidência (BASTO 207, p. 91-92).

Com o final da Segunda Guerra Mundial ${ }^{29}$ e ampliação dos esforços no sentido da formação de uma cultura comunitária (da qual decorreu a União Europeia), havia a necessidade de unificação da tributação indireta ${ }^{30}$. Ela era responsável por grande parte das distorções fiscais às trocas internacionais ${ }^{31}$.

Assim que as nações periféricas daUnião Europeia aceitaram a introdução do IVA, passou-se à reforma de forma gradual, contínua, porém completa, em seus sistemas fiscais $^{32}$. Inicialmente, com a eliminação de alguns impostos especiais (as accises), como ocorria sobre o café e espetáculos, por exemplo. (DE BASTO, 2007, p. 94). Em seguida, foi importante a criação de uma base de incidência uniforme (denominada assiette uniforme) (DE BASTO, 2007, p. 95) entre todos os Estados integrantes da União Europeia (GUIMARÃES, 2007, p. 56).

Desta maneira, a forma de incidência do imposto passou a ser, aos poucos, semelhante, em todos os locais do bloco

A fase seguinte consistiu na centralização na tributação ind ireta ${ }^{33}$, em paralelo aos movimentos descentralizadores ocorridos nos impostos sobre o patrimônio e a renda

29 “O IVA surgiu na França porvolta do ano de 1954, hoje é a plica do em mais de uma centena de países". (ÁGUIA, 2007,p. 124)

30 "A circunstância de a harmoniza ção tributá ria na União Europeia se centrar muito na tributação indirecta em explicação pela relação imediata que existe entre os impostos indirectos e os preços dos bens transaccioná veis, o que impõe uma rigorosa coordenação internacional, se se querem evitar distorções de origem fiscal às trocas interna ciona is numa á rea integra da". (BASTO, 2007,p. 93)

31 Ricardo Calle Sainz explica que a harmonização "Es también um reflejo de la estructura económica del país y de la distribución de la renta nacional... Es decir, que la unificación completa de los sistemas fiscales supondría no solo uma identidad de estructuras económicas y sociales, sino también uma similitud de las conductas psicológicas y sociológicas". (SAINZ, 1971).

É também um reflexo da estrutura econômica do país e da distribuição da renda nacional... Significa que a unificação completa dos sistemas fisca is suponha não somente uma identidade de estruturas econômic as e sociais, mas ta mbém uma semelhança dos comportamentos psicológicos e sociológicos. (tra dução nossa) 32 “A versão inicial da Constituição [portuguesa] de 1976, de ca riz socia liza nte, [...] cria çã o, em substituição dos impostos cedulares vigentes, de um imposto sobre o rendimento pessoal, único e progressivo, tendo por objectivo a diminuição das desigualdades”. (DOS SANTOS, 2007, p. 225)

33 "Inicialmente os países-membros determinariam o tipo de Imposto sobre o Valor Agregado que seria introduzido em seus sistemas tributários [...] em uma segunda etapa proceder-se-ia à harmonização progressiva." (MEIRELLES, 2000,p. 127).

Campo Jurídico|Barreiras (BA)| v.9 |e664| p.01-22 |Janeiro-Junho|2021 
(direta) (DOS SANTOS, 2007, p. 253). Em seguida, com o fim de assegurar um mercado comum europeu, foi estabelecida uma nova isenção: para a aquisição de bens intracomunitária (entre os países) na União Europeia ${ }^{3435}$.

Frise-se que a harmonização tributária na União Europeia não foi um fim em si mesmo, mas um mecanismo para a integração comunitária - objetivo maior do Tratado de Roma (DE BASTO b, 1991, p. 20). Isto porque é um pacto realizado entre Estados, e não entre governos. Estes são forçados ao comprimento, e dessa forma a gestão tecnocrática tende a ser valorizada (DOS SANTOS, 2007, p. 252-253) ${ }^{36}$.

Para alçar tal nível de solidez e respeitabilidade do novo modelo, não bastariam singelas alterações, ou mesmo que elas ocorressem sem a participação popular. Foram necessárias inúmeras discussões e documentos (MEIRELLES, 2000, p. 128), que se materializaram em formas de "Directivas". A provaram-se mediante a unanimidade dos EM (Estados-Membros), e apenas obrigam os Estados quanto aos fins a serem atingidos - permanecendo eles livres quanto aos mecanismos utilizados (BASTO, 2007, p. 94).

A primeira Diretiva definiu o IVA, estabelecendo-o como imposto geral (BASTO, 2007, p. 105), estendido a todos os estágios de produção e oferta de bens e serviços, pois simples e neutro (COSTA, 2014, p. 18). O método de cálculo adotado foi o substrativo indireto ${ }^{37}$.

Após os avanços da Primeira Diretiva IVA, foi criada a Segunda, com 21 artigos organizando as bases do próprio imposto, utilizadas até a atualidade. Por exemplo,

\footnotetext{
34 "Um novo facto gerador de imposto, a figura da aquisição intra comunitária de bens. Para lelamente, em vez da isenção nas exportações, passou a prever-se a isenção nas transmissões intra comunitárias de bens". (DOS SANTOS, 2007,p. 231)

35 É importante constatarque a Europa, com diversidade étnica, linguística e conflitos regionais seculares, harmonizou a tributação indireta, mas não o fez o Brasil.

${ }^{36}$ Consequência relevante foi que: "a os poucos, com a integra ção fiscal e econômica, o tributo "se impôs definitiva mente no universo das finanças pública s”. (FALCÃO, 2007, p. 612)

${ }^{37}$ Explica a literatura que "Os métodos [de cálculo] são: métodos diretos e indiretos; a ditivos e substrativos; o método indireto substrativo".

Utilizou a seguinte fórmula de cálculo do imposto a pagar $(\mathrm{T})$ : $\mathrm{T}=\mathrm{t}(\mathrm{R}-\mathrm{C})$, significando o modelo acima que "a alíquota do imposto (t) aplica-se ao valor agregado (V), que é a diferença (subtração) entre as receitas das vendas $(\mathrm{R})$ e o valor totaldas compras rea liza das com outra s empresas $(\mathrm{C})$ ”.

Tendo em vista que o valor agregado $(\mathrm{V})=(\mathrm{R}-\mathrm{C})$, a consequência é que $\mathrm{T}=\mathrm{t} . \mathrm{V}$, no modo substrativo. permite o método o crédito do imposto já adimplido por outrem. Passará a ser considerado o gra vame das aquisições t e o gravame das vendas t', para que se obtenha a fórmula: $T=t$ 'R -tC Sendo que, sempre que $\mathrm{t}$ '=0, T será igual a tC. No modelo aditivo, por sua vez, $\mathrm{V}$ será igual a $\mathrm{W}+\mathrm{I}+\mathrm{P}$ e $\mathrm{T}=\mathrm{t}(\mathrm{W}+\mathrm{I}+\mathrm{P})$. (LOPES, 2006, p. 45-52).

"Com a utilização do método indireto substrativo ou método do crédito de imposto, ou ainda das faturas, temos o valor do imposto a plicando a alíquota a valor das receitas das vendas e subtraindo ao resultado obtido o imposto suportado nas compras: T = T.R-t.C. Logo podemos concluir que tanto nos métodos indiretos como nos métodos diretos: $\mathrm{T}=\mathrm{t} . \mathrm{V}$, ou seja, teremos sempre a tributação do valor agrega do". (LOPES, 2006,p. 47)
}

\section{Campo Jurídico|Barreiras (BA)| v.9 |e664| p.01-22 |Janeiro-Junho|2021}


trouxe a noção de transmissão dos bens e prestação de serviços e a sua relação com a emissão das faturas (COSTA, 2014, p. 19). Esta Directiva apresentou características conceituais e práticas, concomitantemente.

A Terceira Directiva não alterou a substância do novo imposto, mas apenas prorrogou o prazo de adoção entre os EM do início de 1970 para 1972 (COSTA, 2014, p. 19). A quarta e a quinta também restaram limitadas a prorrogações de prazos, estendendo os limites para que a Itália adotasse o IVA (COSTA, 2014, p. 20).

A sexta diretiva foi a mais importante de $\operatorname{todas}^{38}$. Através da formação de um CIVA (Código Comunitário sobre o Imposto sobre o Valor Agregado) (ALEXANDRE, 2007, p. 136), buscou a uniformidade da base de incidência e forte redução da diversidade dos Estados Membros nos aspectos internos de introdução do $\mathrm{IVA}^{39}$. Com a diretiva em análise foi obtida uma abolição das fronteiras fiscais dentro da União Europeia. (PALMA, 2006, p. 13) ${ }^{40}$.

Oito anos depois, mediante análises dos erros e acertos das pequenas reformas anteriores (e assim deve proceder no Brasil, em perene processo de inovação), foi criado o Livro Branco do IVA. Ele trouxe propostas buscando aprofundamento da harmonização (COSTA, 2014, p. 21-22): aplicação da tributação na origem ${ }^{41}$, mediante

\footnotetext{
38 “A decisão mais completa com relação à harmonização do imposto sobre valor a grega do foi adotada em 1977." [Sexta Diretiva] (CANO, 1999,p. 69)

39 Ressalta Alexandra Martins, todavia, que "as normas de incidência, isenções, matéria colectável e dedução previstas na Sexta Directiva [...] são de competência exclusiva da Comunidade e vincula tivas, nos seus exactos termos, para todos os Estados-membros. Existe, todavia, um espaço de livre conformação normativa”. (MARTINS, 2007,p. 299)

40 Antônio Carlos dos Santos assim classifica a Sexta Diretiva de integração da União Europeia mediante o Imposto sobre o Valor Agregado, ou Value Added Tax (VAT): In 1977 the 6th diretive established the second stage of the common system of VAT. One of the rea sons for that change was the introduction of the new system of own resources in the European community, with as important role attributed to VAT. So, VAT becomes a more general consumption tax with the enlargement of taxable operation (taxing the majority of services, agriculture and reducing the number of exemption) the envelopment of VAT process of harmonisation reinforced the main characteristics of this tax and consequently led to an improved process of economic integration. (DOS SANTOS, 2008,p. 62)

Em 1977 a sexta diretiva estabeleceu a segunda fase do sistema comum do IVA. Uma das razões para esta mudança foi a introdução do novo sistema de recursos próprios na comunidade Europeia, com papel tão importante atribuído a IVA. Assim, o IVA torna -se um um imposto sobre o consumo mais geral com o a larga mento das operações tributá veis (tributando a maioria dos serviços, a gricultura e reduzindo o número de exceções) o envolvimento do processo de harmonização do IVA reforçou as principais características deste tributo e consequentemente conduziu a um processo melhorado de integração econômica. (tradução nossa)

41 “A CEE inclina-se pela solução que implica tributação no país de produção do bem, pertencendo a receita, entretanto, a o país onde o bem é consumido". (DAIN, 1995, p. 30)
}

Campo Jurídico|Barreiras (BA) | v.9 |e664| p.01-22 |Janeiro-Junho|2021 
uma câmara de compensação e aproximação das alíquotas, com a criação de uma comum e outra reduzida ${ }^{42}$.

Isto significa que nas vendas intracomunitárias (entre países da União Europeia) o imposto é cobrado no país de origem - isto é, de saída - e não de consumo ${ }^{43}$. No que se refere ao comércio com nações alheias à União Europeia, por outro lado, a alíquota independe do local de saída, assim como as obrigações acessórias. Assim sendo, para tal efeito, o espaço Comunitário se assemelha ao de um único país ${ }^{44}$.

Importando a ideia para o modelo brasileiro, seria interessante a manutenção da tributação no local da origem com fundo único e distribuição justa entre os entes federativos e municípios, a ser promovida pelo convênio deliberativo autônomo proposto. Não ocorreria apenas aproximação das alíquotas, mas uma verdadeira unificação mediante legislação federal.

Outras duas Diretivas foram criadas, sendo a Sétima referente à aplicação do IVA às obras de arte, antiguidades e bens usados; e a Oitava destinada aos não residentes na Comunidade Europeia (MEIRELLES, 2000, p. 128).

A Legislação de base atual é a Diretiva 2006/112/CE, que aplica as mencionadas acima, além de outras criadas com igual fim de uniformização entre os Estados-Membros da União Europeia. Várias recomendações e regramentos vêm sendo atualizados constantemente, a exemplo da COM (2008) 109, que tentou instituir, sem sucesso inicial, um mecanismo generalizado de autoliquidação. As dificuldades residiram na opção por análise das medidas atuais de combate à fraude, armazenamento

\footnotetext{
42 "No IVA Português, no momento, $62 \%$ da base de incidência são tributa das pela alíquo ta geral, de $19 \%$; $12 \%$ da base pela alíquota de $12 \%$ e os restantes $26 \%$ pela alíquota mais baixa, de $5 \%$. Feitas as mesmas contas, uma só alíquota de cerca de $14,5 \%$ permitiria obter o mesmo resultado. A gestão de um sistema múltiplo de alíquotas, a somas às inevitáveis isenções, aumenta significativamente os custos de administração do imposto. [...] [contudo], Uma alíquota única é difícil de defender no 'merca do político.' (DE BASTO, 2007,p. 110)

${ }^{43}$ Especificamente no que se refere ao comércio intracomunitário, há incidência de alíquota $0 \%$, a lém de reembolso do IVA despendido para a exportação, com aplicação completa no estado de destino. $\mathrm{O}$ agente económico tem uma conta corrente com o Estado: debita o IVA que suportou, credita o que recebeu e entrega a diferença ao Estado. O operador, no entanto, possui "direito à dedução transfronteiriça, que permita que um sujeito passivo deduza no seu EM de estabelecimento o IVA aplicado a despesas efectuadas nos EM onde não está estabelecido" (PALMA, 2006, p. 193). Para que isto ocorra, o contribuinte deve cumprir as seguintes obrigações acessórias: "Mencionar na fatura o seu número de IVA com o prefixo identificativo do Estado-membro a partir do qual vão ser transporta dos os bens com destino a outro Estadomembro, e deverá mencionar igualmente o número de IVA do seu cliente, com o prefixo do Esta do -membro que the o atribuiu e que vai ser utilizado na aquisição intracomunitária de bens (ALEXANDRE, 2007, p. 139).

${ }^{4}$ Vasco Branco Guimarães assim ilustra: "não há diferenças de tributação - a não ser logísticas evidentemente - se o exportador europeu exportar pelo porto de Roterdão, de Lisboa, de Cádis ou por outro qualquer porto europeu". (GUIMARÃES, 2007, p. 58)
}

Campo Jurídico|Barreiras (BA) | v.9 |e664| p.01-22 |Janeiro-Junho|2021 
dos dados, teste do novo mecanismo, comparação entre ambos, e, por fim, opção pelo mais vantajoso (COSTA, 2014, p. 26).

Após a exposta evolução europeia em sede de IVA, alcançou-se o modelo aplicado na atualidade. A compatibilização dos sistemas tributários internos, evitando distorções de competitividade, é modelo a ser seguido para o fim da guerra fiscal no Brasil (MEIRELLES, 2000, p. 123).

Especial adendo deve ser exposto em relação aos reflexos positivos do Imposto sobre o Valor Agregado sobre a economia e o federalismo alemão. Em relação à economia, é beneficiada pelo Billigkeitserlass, atrelado à neutralidade concorrencial, que fundamentou a elaboração do IVA (umsatzsteuer) e a sua ampla adoção pela Corte Constitucional (BVerfG) (COELHO, 1998, p. 287).

Quanto ao federalismo, por sua vez, é marcado pelo cooperativismo ${ }^{45}$. Não obstante os orçamentos públicos sejam conduzidos autonomamente pelos laender/estados (mas com ampla transparência e controle recíproco), as funções de administração do IVA são compartilhadas. A competência para concessão de subsídios está restrita ao governo central, por meio de leis ordinárias.

A repartição das receitas do umsatzsteuer (IVA) alemão depende da legislação ordinária federal ${ }^{46}$. A ideia de compensação financeira horizontal (laenderfinanzausgleich) como um dos critérios de distribuição deve ser evidenciada na reforma brasileira, para que haja uniformidade das condições de vida ${ }^{47}$ inter-regionais. Atende-se, desta maneira, à determinação constitucional.

Analisando os reflexos do IVA sobre a integração comunitária europeia e, em especial, interna nas nações que a compõem (com os importantes exemplos português e alemão), conclui-se que, na Europa, tanto os objetivos econômicos quanto os técnicos foram paulatinamente alcançad os ${ }^{48}$.

\footnotetext{
45 Uma lição para o sistema concorrencialautofá gico bra sileiro.

46 Ao contrário do modelo proposto neste trabalho, que seria estabelecido parcialmente na Constituição e mais especificamente em Lei Complementar, com administração e execução pelo convênio deliberativo autônomo.

${ }^{47}$ Cláudio Célio de Araújo Lopes explica, por fim, que na distribuição "os municípios ou associações de municípios teriam uma participação obrigatória nas receitas do imposto sobre o valor agregado (IVA) cabíveis a os seus respectivos laender" (LOPES, 2006,p. 59-61)

${ }^{48}$ Assim expõe Antônio Carlos dos Santos: "From an economic point of view, the main objective of VAT was the deepening of the economic integration process in the European community. From a technical standpoint, the objective was the introduction of neutra lity in consumption taxation and in the organisation of the enterprises in comparison with the existent turnover taxes having cumulative effects".(DOS SANTOS, 2008,p. 61)
}

\section{Campo Jurídico|Barreiras (BA)| v.9 |e664| p.01-22 |Janeiro-Junho|2021}


Contudo, há ainda importantes obstáculos a serem resolvidos na atualidade. Afinal de contas, o processo de atualização do IVA deve ser constante, com novos diagnósticos e propostas ${ }^{49}$.

O documento supramencionado buscou atuar em quatro frentes prioritárias, a serem observadas pela reforma brasileira: um imposto mais simples, com sistema mais eficaz, estrutura mais robusta e imune à sonegação e adaptação ao mercado único (COSTA, 2014, p. 39).

Em relação ao primeiro aspecto, foram sugeridos alguns avanços: primeiramente, aplicação mais alargada de balcões únicos. Ou seja, o importador, independentemente do local de atuação na União Europeia, poderá recolher os tributos em apenas uma localidade, e serão redistribuídos mediante câmara de compensação.

A aplicação de semelhante fundo único no Brasil baratearia o comércio internacional, sem necessidade de alterações nas alíquotas, e ampliaria a competitividade da oferta e do mercado brasileiros. Além disso, trariam mais justiça fiscal a um país com sedes financeiras estabelecidas em São Paulo e descentralização das plataformas de gerenciamento em nível tático e operacional (como as vendas).

Em segundo lugar, busca o Livro Verde o fornecimento aos contribuintes de melhores informações, a nível de UE. Trata-se da tradução dos textos e utilização de imagens, gráficos. Em outros termos, linguagem simples e acessível, em especial para os menores operadores. No Brasil há o exemplo de sucesso do Simples Nacional, que pode servir de base para um sistema semelhante voltado à tributação do consumo. Há a vantagem inicial de desnecessidade de tradução dos textos para os brasileiros.

Quanto ao segundo aspecto, por sua vez, busca o Livro Verde uma ampliação da base fiscal e limitação das taxas reduzidas, assim como das isenções

\footnotetext{
De um ponto de vista econômico, o principal objetivo do IVA foi o aprofundamento do processo de integração econômica na comunidade Europeia. De um ponto de vista técnico, o objetivo foi a introdução da neutralidade na taxação do consumo e a organização dos empreendimentos em comparação com a rotatividade existente dos tributos com efeitos cumula tivos. (tra dução nossa)

49 Nina Gabriela Norges ressalta que a os poucos o modelo voltou a enfrentar "complexidade, burocracia, custos de cumprimento e um grau de harmonização legislativa insuficiente fazem com que o sistema de IVA na União Europeia, a presente muitas deficiências". Complementa ainda:. "i - a existência de distintas interpretações e aplicações práticas das regras do IVA dentro da comunidade; ii - a existência de algumas derrogações ao sistema comum; iii - a burocracia e os custos de cumprimento; iv - o insatisfatório grau de harmonização do imposto - põe em causa o princípio da neutra lida de, abrindo portas a relevantes problemas, concreta mente em relação às distorções de concorrência em diversos domínios." (COSTA, 2014,p. 40)
}

Campo Jurídico|Barreiras (BA)| v.9 |e664| p.01-22 |Janeiro-Junho|2021 
estabelecidas pelos Estados Membros sob a justificativa de "interesse público", mas que distorcem a concorrência intracomunitária ${ }^{5051}$.

Sobre o terceiro e quarto pontos, o Livro Verde aborda um sistema IVA mais sólido, robusto e imune à fraude (COSTA, 2014, p. 40) $)^{52}$ - em especial à fraude carrossel. Para tal, busca que a integralização dos dados no sistema ocorra de forma imediata, e não a cada três meses, e que haja restrições especiais à elisão fiscal abusiva ${ }^{5354}$.

Outro problema verificado no atual IVA Europeu é a falta de rapidez na troca de informações. Especula-se que ocorra em virtude da ausência de receita de imposto adicional gerada para o Estado-Membro requerido - logo, ele adia a resolução das questões apresentadas pelos demais (ALEXANDRE, 2007, p. 145).

Para a resolução de semelhante questão no Brasil, deve-se integrar a rapidez e qualidade na troca de informações e fiscalização entre os entes federativos como um dos aspectos da variante "qualidade da administração e fiscalização do IVA". Este seria um dos fatores estabelecidos por Emenda Constitucional ou em Lei Complementar para a fixação do montante do fundo único geral a ser repassado para a União, Estado, DF ou Município.

A perspectiva para o futuro do Imposto sobre o Valor Agregado Europeu consiste em um regime direcionado para pequenas empresas, com uma faixa de isenção e auxílio nas obrigações acessórias, para que possam exportar ${ }^{55}$. A unificação da faixa de

\footnotetext{
50 Todavia, no que se refere especificamente à s derrogações atribuídas por entidades privadas, Alexandra Martins ressalta que "Dificilmente se justificaria que a interpretação do alcance do termo "subvenção", utilizado na Sexta Directiva, se a larga sse às libera lidades a tribuída s por entidad es priva da s” (por exemplo, parafiscalidade). Portanto, defende um controle menos rígido que o referente à s pessoas jurídicas de direito público ou por elas subvencionadas. (MARTINS a, 2007,p. 328)

51 Por exemplo, "Uma redução em 50 por cento da diferença da estrutura das taxas de IVAentre os Estados membros poderia conduzir a um aumento de 9,8 por cento no comércio intra -UE" (COSTA, 2014, p. 3940)

52 “A adequação deles importa, por vezes, na quebra de métodos tra diciona is de exação.” (MEIRELLES, 2000,p. 123)

53 Com o objetivo específico de evitar a fraude à lei, Alexandra Martins propõe a criação de "nomas nacionais antiabuso devem ter em consideração os objectivos prosseguidos pelas disposições comunitárias". (MARTINS a, 2007,p. 287)

54 No Brasil há importante avanço contra o abuso das formas, mediante a teoria do propósito negocial, insculpida a tra vés da "norma geral antielisão" no art. 116 do Código Tributário Nacional. É uma "Clá usula geral antiabuso [...] sua validade jurídica a ssente numa concepção de tipicidade aberta coordenada com a aplicação do princípio da igualdade, bem como numa distinção meramente gradativa da a nalogia em face da interpretação extensiva no processo hermenêutico." (MARTINS a, 2007,p. 299).

${ }^{55}$ Um regime específico das pequenas empresas, que permite a os Esta dos-membros aplica rem uma isenção fiscal a os sujeitos passivos cujo volume de negócios não excede um limiar determinado" (PALMA, 2007, p. 192)
}

Campo Jurídico|Barreiras (BA) | v.9 |e664| p.01-22 |Janeiro-Junho|2021 
isenção pode estar atrelada aos conceitos de direito empresarial (MEI, por exemplo.) para aplicação no Brasil.

\section{CONCLUSÕES}

Diante do estudo realizado, observou-se a validação parcial das hipóteses iniciais. Foi verificada a importância da integração político-econômica para o desenvolvimento dos mercados e efetivação das políticas sociais. Para estimular a cooperação entre os entes federativos e também os municípios, relevante a adoção da rapidez e qualidade na troca de informações e fiscalização entre os entes como um dos aspectos da variante “qualidade da administração e fiscalização do IVA”. Este, um dos critérios para a quantidade de repasse do tributo.

Para a integração intergovernamental e facilitação do cumprimento das obrigações acessórias, necessária a unificação da tributação do consumo, mediante utilização de: idêntica hipótese de incidência/fato gerador, com aspecto temporal equânime, apenas um sujeito ativo da obrigação tributária, e apenas uma alíquota e base de cálculo, em todo o território nacional.

Além disso, a transação interestadual de bens e serviços não deve constituir fato gerador do Imposto sobre o Valor Agregado: a simples alienação já corresponderia legalmente à hipótese de incidência. Não haveria diferença, portanto, entre a prática comercial dentro ou fora do mesmo estado. Entretanto, o contribuinte deverá relatar na declaração doIV A o adquirente e o seu estado (à exceção das transações entre sociedades empresárias e consumidores, em que só deverá apresentar o estado do comprador), com o fim de promover o controle da sonegação e elisão abusiva.

Quanto às transações internacionais, relevante a contribuição europeia sobre o fim dos gravames indiretos aos exportadores, que constituem verdadeiros resquícios da cumulatividade, com a substituição do crédito físico pelo financeiro, por exemplo. Em especial, quanto ao uso de balcões únicos na importação e exportação, com identificação no registro da transação, pelo contribuinte de direito, do estado e município do qual se destinou ou ao qual se destinará o bem. Isto será inclusive útil para a distribuição imediata do fund o único entre União, Estados, DF e Municípios.

Para a efetiva concretização do tributo, com mudança no comportamento da Administração e dos contribuintes (especialmente os menores), importante o uso de

\section{Campo Jurídico|Barreiras (BA)| v.9 |e664| p.01-22 |Janeiro-Junho|2021}


linguagem clara e acessível. Para este fim, deve-se utilizar imagens, gráficos e setor especializado de atendimento ao público. Da experiência brasileira é possível aproveitar o modelo utilizado no Simples Nacional.

Como vantagem para a mudança no comportamento, a atualização de dados no sistema pelos próprios contribuintes (com a declaração do IVA) deve corresponder ao controle imediato e informatizado, sem necessidade de ação humana para a maior parte das detecções de fraudes. É importante ainda a integração deste sistema com um maior, para o MERCOSUL - para permitir que os pequenos operadores exportem e se relacionem com sociedades empresárias de outros países.

Um regime específico para pequenos operadores também deve ser adotado, com faixa de isenção para microempresas, quando atuarem como contribuintes de direito (mas não de fato, assim como ocorre na atualidade em relação às imunidades subjetivas, por exemplo). A isonomia fiscal depende de uma ampliação da base fiscal e limitação das isenções taxas reduzidas, bem como evolução gradativa dojá adotado critério do business porpose (propósito comercial), para evitar a elisão fiscal.

Desse modo, a relevante lição europeia demostra o dever de uma introdução de forma gradual e contínua, porém completa, no âmbito tributário. Ou seja, o sistema necessita de processo de constante evolução, mediante alterações pontuais como respostas a diagnósticos realizados por especialistas e pelos contribuintes em geral.

Portanto, há importante vantagem brasileira que facilita a concretização do IVA: a unidade linguística e aproximação entre os entes federativos, através de convênios. Além disso, trata-se de um único país - com alguns sistemas tributários parecidos, e outros, nem tanto. O diálogo entre os entes pode permitir a adoção do IVA no Brasil, atrelando-o ao modelo já adotado nos demais países do Mercosul, assim como ocorrido dentro da União Europeia.

\section{REFERÊNCIAS}

ÁGUIA, José Maurício Pereira. Imposto sobre Valor Agregado: abordagem teórica e prática. Em: SARAIVA FILHO, Oswaldo Othon de Pontes; VASQUES, Sérgio; GUIMARÃES, Vasco Branco (org.). IVA para o Brasil: contributos para a reforma da tributação do consumo. Belo Horizonte: Fórum, 2007. P. 123-134

ALEXANDRE, Mário Alberto. O controle do IVA nas transações intracomunitárias de bens na União Européia: a troca de informações como base fundamental para o acompanhamento do cumprimento da obrigação tributária dos contribuintes. Em:

Campo Jurídico|Barreiras (BA)| v.9 |e664| p.01-22 |Janeiro-Junho|2021 
SARAIVA FILHO, Oswaldo Othon de Pontes; VASQUES, Sérgio; GUIMARÃES, Vasco Branco (org.). IVA para o Brasil: contributos para a reforma da tributação do consumo. Belo Horizonte: Fórum, 2007. P. 135-156

BALTHAZAR, Ubaldo César. A gênese do imposto sobre o valor agregado. Em: Revista Seqüência, v. 29, n. 56 (2008). Florianópolis: UFSC.

BARRERA, Aglas Watson; RORAELLI, Maria Liz de Medeiros. Relações fiscais intergovernamentais. Em: AFFONSO, Rui de Britto Álvares; SILVA, Pedro Luiz Barros (org.). Reforma tributária e federação. São Paulo: FUNDAP. 1995. P. 129-160

CANO, Hugo González. A harmonização tributária em processos de integração econômica. Brasília: ESAF. 1999.

CARDOZO, Soraia Aparecida.. Guerra fiscal no Brasil e alterações das estruturas produtivas estaduais desde os anos 1990. Campinas: UNICAMP. 2010.

CHANGA, Aboocar Zainadine Dauto. A implementação do IVA em Moçambique. Em: SARAIVA FILHO, Oswaldo Othon de Pontes; VASQUES, Sérgio; GUIMAR ̃̃ES, Vasco Branco (org.). IVA para o Brasil: contributos para a reforma da tributação do consumo. Belo Horizonte: Fórum, 2007. P. 463-526

CNOSSEN, Sijbren. Taxing Value Added: the OECD experience. Amsterdam: International VAT Monitor. 1990.

COÊLHO, Sacha Calmon Navarro. O IVA Brasileiro. Em: SARAIVA FILHO, Oswaldo Othon de Pontes; VASQUES, Sérgio; GUIMARÃES, Vasco Branco (org.). IVA para o Brasil: contributos para a reforma da tributação do consumo. Belo Horizonte: Fórum, 2007. P. 553-586

COSTA, Nina Gabriela Borges. A Implantação do IVA no Brasil: oportunidades e dificuld ades de contexto. Em: $2^{\circ}$ Ciclo de Estudos em Direito. Coimbra: Faculdade de Direito da Universidade de Coimbra. 2014.

COURCHENE, T. J. Federalismo e a nova ordem econômica: uma perspectiva dos cidadãos e dos processos. Em: REZENDE, F.; OLIVEIRA, F. A. Federalismo e integração econômica regional: desafios para o Mercosul. Rio de Janeiro: Konrad Adenauer. 2004.

DAIN, Sulamis. Experiência internacional e especificidade brasileira. Em: AFFONSO, Rui de Britto Álvares; SILVA, Pedro Luiz Barros (org.). Reforma Tributária e Federação. São Paulo: FUNDAP. 1995.

DE ALMEIDA, Sand ra Cristina Filgueiras; CAVALCANTI, Carlos Eduardo Gonlçalves. As Contribuições Sociais e a Reforma Tributária. Em: AFFONSO, Rui de Britto Álvares; SILVA, Pedro Luiz Barros (org.). Reforma Tributária e Federação. São Paulo: FUNDAP. 1995. P. 97-128.

DE BASTO, José Xavier. A adopção do sistema comum europeu de Imposto sobre o Valor Acrescentado (IVA) em Portugal. Em: SARAIVA FILHO, Oswaldo Othon de Campo Jurídico|Barreiras (BA)| v.9 |e664| p.01-22 |Janeiro-Junho|2021 
Pontes; VASQUES, Sérgio; GUIMARÃES, Vasco Branco (org.). IVA para o Brasil: contributos para a reforma da tributação do consumo. Belo Horizonte: Fórum, 2007. P. 89-122.

DE BASTO, José Guilherme Xavier. Temas de integração. Tendência de Evolução dos Sistemas Fiscais na União Com Especial Referencia ao Imposto sobre o Valor Agregado (IVA). Em: Caderno de ciência e técnica fiscal, n. 164 (abr 1991). Coimbra: Direção Geral de Impostos (DGCI).

DERZI, Misabel Abreu Machado; SANTIAGO, Igor Mauler. A harmonização dos IVAs do Brasil para o desenvolvimento produtivo. Em: SARAIVA FILHO, Oswaldo Othon de Pontes; VASQUES, Sérgio; GUIMARÃES, Vasco Branco (org.). IVA para o Brasil: contributos para a reforma da tributação do consumo. Belo Horizonte: Fórum, 2007. P. $527-522$

DOS SANTOS, António Carlos. Implicações do processo de integração de Portugal na Comunidade Europeia nas políticas fiscal e orçamental. Em: SARAIV A FILHO, Oswaldo Othon de Pontes; VASQUES, Sérgio; GUIMARÃES, Vasco Branco (org.). IVA para o Brasil: contributos para a reforma da tributação do consumo. Belo Horizonte: Fórum, 2007. P. 221-258

FALCÃO, Maurin Almeida. Da tributação cumulativa ao Imposto sobre o Valor Agregado: o percurso notável da inovação tributária do século XX. Em: SARAIVA FILHO, Oswaldo Othon de Pontes; VASQUES, Sérgio; GUIMARÃES, Vasco Branco (org.). IVA para o Brasil: contributos para a reforma da tributação do consumo. Belo Horizonte: Fórum, 2007. P. 611-626.

FIGUEIRAS, Marcos Simão. A harmonização tributária no Mercosul e o IVA: imposto sobre o valor acrescido. Em: Revista de Estudos Jurídicos, v.1, n.1 (1996). Franca: UNESP.

GALBRAITH, John Kenneth. A Sociedade Justa: uma perspectiva humana. Trad. KORYTOWSKI, Ivo. Rio de Janeiro: Campus, 1996.

GUIMARÃES, Vasco Branco. A tributação do consumo no Brasil: uma visão europeia. Em: SARAIVA FILHO, Oswaldo Othon de Pontes; VASQUES, Sérgio; GUIMARÃES, Vasco Branco (org.). IVA para o Brasil: contributos para a reforma da tributação do consumo. Belo Horizonte: Fórum, 2007.

LIMA, Edilberto Carlos Pontes. Reforma tributária no Brasil: entre o ideal e o possível. Brasília: Instituto de Pesquisa Econômica Aplicada. 1999.

LOPES, Cláudio Célio de Araújo. O modelo IVA de tributação como instrumento para um novo federalismo fiscal brasileiro diante da globalização. Fortaleza: Fund ação Edson Queiroz e UNIFOR, 2006.

LYNCH, Frances. Funding the modern state: the introduction of value added tax in France. Chiusano di San Domenico: European University Institute. 1997.

Campo Jurídico|Barreiras (BA) | v.9 |e664| p.01-22 |Janeiro-Junho|2021 
MACIEL, Everardo. Propostas de reforma tributária. Brasília: Revista do Centro de Estudos Judiciários do Conselho da Justiça Federal, v. 7, n. 22 (set 2003). P. 31-34. Disponível

https://www.lexml.gov.br/urn/urn:lex:br:rede.virtual.bibliotecas:artigo.revista:2003;100 0690621. Acesso em 13 nov 2020.

MARTINS, Alexandra. A admissibilidade de uma cláusula geral antiabuso em sede de IVA. Em: SARAIVA FILHO, Oswaldo Othon de Pontes; VASQUES, Sérgio; GUIMARÃES, Vasco Branco (org.). IVA para o Brasil: contributos para a reforma da tributação do consumo. Belo Horizonte: Fórum, 2007. P. 259-310.

MARTINS, Ives Gandra da Silva. Um IVA possível em um sistema tributário justo. Em: SARAIVA FILHO, Oswaldo Othon de Pontes; VASQUES, Sérgio; GUIMARÃES, Vasco Branco (org.). IVA para o Brasil: contributos para a reforma da tributação do consumo. Belo Horizonte: Fórum, 2007. P. 397-406

MEIRELLES, José Ricardo. Impostos indiretos no Mercosul e integração. São Paulo: LTr. 2000.

MONTORO FILHO, André F. Contabilidade social: uma introdução à macroeconomia. São Paulo: Atlas, 1992.

PALMA, Clotilde Celorico. A harmonização comunitária do Imposto sobre o Valor Agregado: quo vadis. Em: SARAIVA FILHO, Oswaldo Othon de Pontes; VASQUES, Sérgio; GUIMARÃES, Vasco Branco (org.). IVA para o Brasil: contributos para a reforma da tributação do consumo. Belo Horizonte: Fórum. 2007. P. 175-220.

QUADROS, Waldemir Luis de. A tributação indireta no Brasil. Em: AFFONSO, Rui de Britto Álvares; SILVA, Pedro Luiz Barros (org.). Reforma tributária e federação. São Paulo: FUNDAP. 1995. P. 75-96.

SAINZ, Ricard o Calle. La Armonización Fiscal europea y el Impuesto sobre el Valor Añadido. Em: El Impuesto sobre el Valor Añadido: primer impuesto europeo . Madrid: Instituto de Estudios Fiscales de la Fabrica Nacional de Moneda y Timbre Ministério de Hacienda. 1971.

SCHULTZ, Adriane (e outros). Mais da metade dos deputados federais eleitos é a favor da adoção do imposto único. G1, Grupo Globo, Nov. 2018. Disponível em: htps://g1.globo.com/politica/noticia/2018/11/27/mais-da-metade-dos-deputad osfederais-eleitos-e-a-favor-da-adocao-do-imposto-unico.ghtml. Acesso em 05 dez 2020.

SOLDATI, Emanoelle Brasil. Implantação do IVA no sistema tributário brasileiro: uma visão do Mercosul. Coimbra. Dissertação de Mestrado da Faculdade de Direito da Universidade de Coimbra. 2006.

TORRES, Ricardo Lobo. É possível a criação do IVA no Brasil? Em: SARAIVA FILHO, Oswaldo Othon de Pontes; VASQUES, Sérgio; GUIMARÃES, Vasco Branco (org.). IVA para o Brasil: contributos para a reforma da tributação do consumo. Belo Horizonte: Fórum, 2007. P. 19-36.

Campo Jurídico|Barreiras (BA) | v.9 |e664| p.01-22 |Janeiro-Junho|2021 